\title{
Article \\ The Difference in Subjective Experience Related to Acoustic Treatments in an Ordinary Public Room: A Case Study
}

\author{
Emma Arvidsson ${ }^{1, *(\mathbb{C}}$, Erling Nilsson ${ }^{2}\left(\mathbb{D}\right.$, Delphine Bard Hagberg ${ }^{1}\left(\mathbb{D}\right.$ and Ola J. I. Karlsson ${ }^{2}(\mathbb{D}$ \\ 1 Engineering Acoustics, Lund University, John Ericssons väg 1, 22100 Lund, Sweden; \\ Delphine.Bard@construction.lth.se \\ 2 Saint-Gobain Ecophon AB, Yttervägen 1, 26575 Hyllinge, Sweden; erling.nilsson@ecophon.se (E.N.); \\ ola.karlsson@ecophon.se (O.J.I.K.) \\ * Correspondence: emma.arvidsson@construction.lth.se
}

Citation: Arvidsson, E.; Nilsson, E.; Bard Hagberg, D.; Karlsson, O.J.I. The Difference in Subjective Experience Related to Acoustic Treatments in an Ordinary Public Room: A Case Study. Acoustics 2021, 3, 442-461. https:// doi.org/10.3390/acoustics3020029

Academic Editor: Dario D'Orazio

Received: 20 April 2021

Accepted: 12 June 2021

Published: 18 June 2021

Publisher's Note: MDPI stays neutral with regard to jurisdictional claims in published maps and institutional affiliations.

Copyright: (c) 2021 by the authors. Licensee MDPI, Basel, Switzerland. This article is an open access article distributed under the terms and conditions of the Creative Commons Attribution (CC BY) license (https:// creativecommons.org/licenses/by/ $4.0 /)$.

\begin{abstract}
In ordinary public rooms absorbent ceilings are normally used. However, reflective material such as diffusers can also be useful to improve the acoustic performance for this type of environment. In this study, different combinations of absorbers and diffusers have been used. The study investigates whether a test group of 29 people perceived sound in an ordinary room differently depending on the type of treatment. Comparisons of the same position in a room for different configurations as well as different positions within one configuration were made. The subjective judgements were compared to the room acoustic measures $T_{20}, C_{50}$ and $G$ and the difference in the values of these parameters. It was found that when evaluating the different positions in a room, the configuration including diffusers was perceived to a greater extent as being similar in the different positions in the room when compared to the configuration with absorbers on the walls. It was also seen that $\mathrm{C}_{50}$ was the parameter that mainly affected the perception, with the difference needing to be $2 \mathrm{~dB}$ to recognize a difference. However, the room acoustic measurements could not fully explain the differences obtained in perception. In addition, the subjective sound image created by different types of treatments was also shown to have an important impact on the perception.
\end{abstract}

Keywords: acoustic perception; subjective acoustics; speech clarity; sound strength; reverberation time; room acoustic design

\section{Introduction \\ 1.1. Room Acoustics in Ordinary Rooms}

In ordinary public rooms - such as classrooms - there is often sound absorbing material chosen as the only acoustic treatment. A high degree of absorbent material, normally used in order to lower the reverberation time, can risk attaining a too low speech level. In the acoustic design of performance spaces, the sound strength is normally controlled [1-3]. The sound strength describes how the room responds to the sound source and is described in the ISO standard 3382-1 for performance spaces [4].

In a room for speech, such as a classroom, is it important that the sound energy level is sufficiently high to ensure that everyone in the audience receives the information being transmitted [5]. It is also important that the speaker can be provided with vocal support. Teachers report voice problems to a greater extent than the rest of the population [6]. A parameter room gain, $G_{R G}$, has been developed in order to evaluate speaker comfort [7-9].

Another important parameter to consider in rooms for speech is the speech clarity, $\mathrm{C}_{50}$, accounting for the ratio of early reflections. The quality of the speech will be dependent on the reflection pattern and the early reflections will contribute to the direct sound [10]. In a study by Bradley et al. [11] the recommendation for rooms for speech was to focus rather on increasing the early reflections than on lowering the reverberation times. Furthermore, it was found by Bradley and Reich that $\mathrm{C}_{50}$ can to some extent complement a low $\mathrm{S} / \mathrm{N}$ [12]. 
As mentioned above, too large quantity of absorbers can cause an excessively low sound energy level, providing the speaker with less support and the listener with less information. It has been shown in model scale [13,14] and further in full scale mock-up [15], that a combination of absorbers and diffusers can be used in order to fine-tune different room acoustic parameters. The diffusers can be used to affect the reflection path without decreasing the energy level. The importance of using both absorption and diffusion or scattering has also been recognized in standards [16,17].

In a study by Azad et al. [18] it was tested how room acoustic parameters were affected if the diffusing element directs the sound toward an absorptive area in a nondiffuse room. It was found that the placement of absorptive material is an important factor to consider $[19,20]$. However, in a study by Shtrepi et al. [21] the location of a diffusive element varied and showed no significant changes in objective room acoustic measurements. Further, it was found in a previous study in this research program [15] that more uniform acoustic properties were obtained using a combination of absorbers and diffusers compared to when only absorptive material was used.

\subsection{Room Acoustics and Subjective Experience}

It is necessary to understand how different room acoustic properties affect people in order to be able to correctly design acoustic environments. Acoustic properties may differ in different positions in a room, which must also be considered. In terms of diffusing elements, Visentin et al. investigated whether there is a difference in perception for surface responding with diffuse or specular reflections, finding that better speech intelligibility was obtained with a diffuser [22]. In a study by Shtrepi et al. [21] no sensitivity between listening positions could be found with different locations of a diffuse element. However, differences in terms of reverberance, coloration and spaciousness were reported. In another study by Shtrepi et al. [23], it was found that the distance from the diffuser surface did have an effect; a distance of $2.15 \mathrm{~m}$ was found to be the threshold for when the listener will no longer perceive the diffusing effect, with the distance depending on the distance to the source position.

Visentin et al. raised the question as to how listening effort could be part of the acoustic design in rooms for speech [24]. In that study it was found how the listening effort differed when room acoustic properties were changed in an Italian university classroom. The question of whether a diffuser and an absorber cause different subjective experience in a conference room was investigated in a study by Sanavi et al. [25] and showed that addition of each of these treatments improved the acoustic experience; however, the absorber was rated better in this study. The room acoustic properties seem to be even more sensitive for non-native listeners; the score can still be good, but rating of effort is higher [26].

Several studies have shown how acoustic properties affect cognitive skills. It is well known that noise disturbs concentration, but cognitive performance is also affected by the sound environment [27-29]. An important finding from these studies is that a more distracting sound environment does not necessarily cause more errors, but greater effort is needed in order to perform the task. The ability to remember and process information is more sensitive than the perception of single words [30]. In specific relation to early reflections, Puglisi et al. examined the effect on the reading ability of Italian second graders, finding that the early reflection ratio could be correlated to reading tasks [31]. The acoustic environment can also be related to well-being [32].

In ISO 3382-1 for performance spaces, the just noticeable differences for different room acoustical parameters are described. It has been found that the just noticeable difference (JND), i.e., the difference needed to experience a difference of the sound, differs for different frequencies and types of music [33]. Further, it is important to consider the values in different positions and not only on an average level. Regarding the importance of good speech clarity, Bradley and Reich investigated [34] the JND for $\mathrm{C}_{50}$ in rooms for speech, finding that $3 \mathrm{~dB}$ is more relevant for these types of rooms than the $1 \mathrm{~dB}$ value stated in the 
standard 3382-1 for performance spaces. However, JND for speech and in ordinary room is not fully understood.

\subsection{Study Objective and Principal Conclusion}

In a previous stage of this research [15] it was investigated how different acoustic treatments, affect room acoustic parameters in a classroom. It was concluded from the study that different type of treatments can be used to fine tune different room acoustic parameters, depending on the need. This has been followed up by investigating if people subjectively can experience a difference of a speech, which is presented in this paper. The aim of the study is to investigate whether people can perceive a difference in relation to different positions and different configurations. Furthermore, to investigate if the participant's subjective experiences can be related to the differences in the room acoustic parameters $\mathrm{T}_{20}, \mathrm{C}_{50}$ and $\mathrm{G}$. To find the preferred solution is not within the scope of this investigation.

A mock-up of a classroom in a laboratory environment was used. In total, five different acoustic treatment configurations were evaluated. All of these have an absorptive ceiling and are sparsely furnished. Variations comprise different acoustic treatment on walls, sound absorbing tiles and diffusing elements, differently oriented. In one configuration, the absorbing ceiling tiles in the area over the source, i.e., speaker, position were replaced with diffusers. Absorbing tiles were applied on the walls in this configuration.

The perception results were compared to room acoustic parameters in order to evaluate whether differences in perception were related to room acoustic parameters or whether the sound image perceived should be related to other descriptors or attributes. It was found that the sound was perceived most similar in configurations with diffusers compared to configuration with only absorbers. To obtain differences in perception, changes mainly in $C_{50}$ were needed. This study does show that the difference should be $2 \mathrm{~dB}$ in $\mathrm{C}_{50}$ for a significant difference in perception.

\section{Materials and Methods}

Experiments were performed in a mock-up area in a laboratory environment with dimensions $7.32 \mathrm{~m} \times 7.57 \mathrm{~m} \times 3.50 \mathrm{~m}$. The area was furnished to simulate a typical classroom. Room acoustic measurements were performed in this environment as well as recordings for the listening test. The listening test was made in another, neutral room. In the following section, the acoustic materials used in the study are presented, as well as how these materials are combined in different configurations. This is followed by descriptions of the room acoustic measurements as well as the listening test procedure.

\subsection{Acoustic Treatment}

\subsubsection{Porous Absorber}

The absorbing material used in the ceiling panels and wall panels is a glass wool product with a thickness of $40 \mathrm{~mm}$ and air flow resistivity of $40 \mathrm{kPas} / \mathrm{m}^{2}$. The material's practical absorption coefficient, $\alpha_{p}$, measured according to ISO 354 [35] and evaluated according to ISO 11654 [36] can be seen in Figure 1. The absorption performance is shown for the overall depth (ODS) of $200 \mathrm{~mm}$, according to specification in standard, as well as for ODS of $50 \mathrm{~mm}$, which represents the behavior of the material when mounted directly on the wall, which is done for Conf 2 and 5 in this investigation, described in Section 2.3 below. The weighted absorption coefficient $\alpha_{\mathrm{w}}$ is equal to 1 for the two different ODS, evaluated in accordance with ISO 11654 [36].

\subsubsection{Diffusers}

The diffusers used were made from a wood frame with a surface of curved hardboard. All diffusers tested had the same geometry and dimensions: $600 \mathrm{~mm} \times 600 \mathrm{~mm} \times 100 \mathrm{~mm}$, see Figure 2. Air gaps at the sides in combination with the enclosed volume give the diffuser resonance absorption properties in the frequency range $125-250 \mathrm{~Hz}$. 


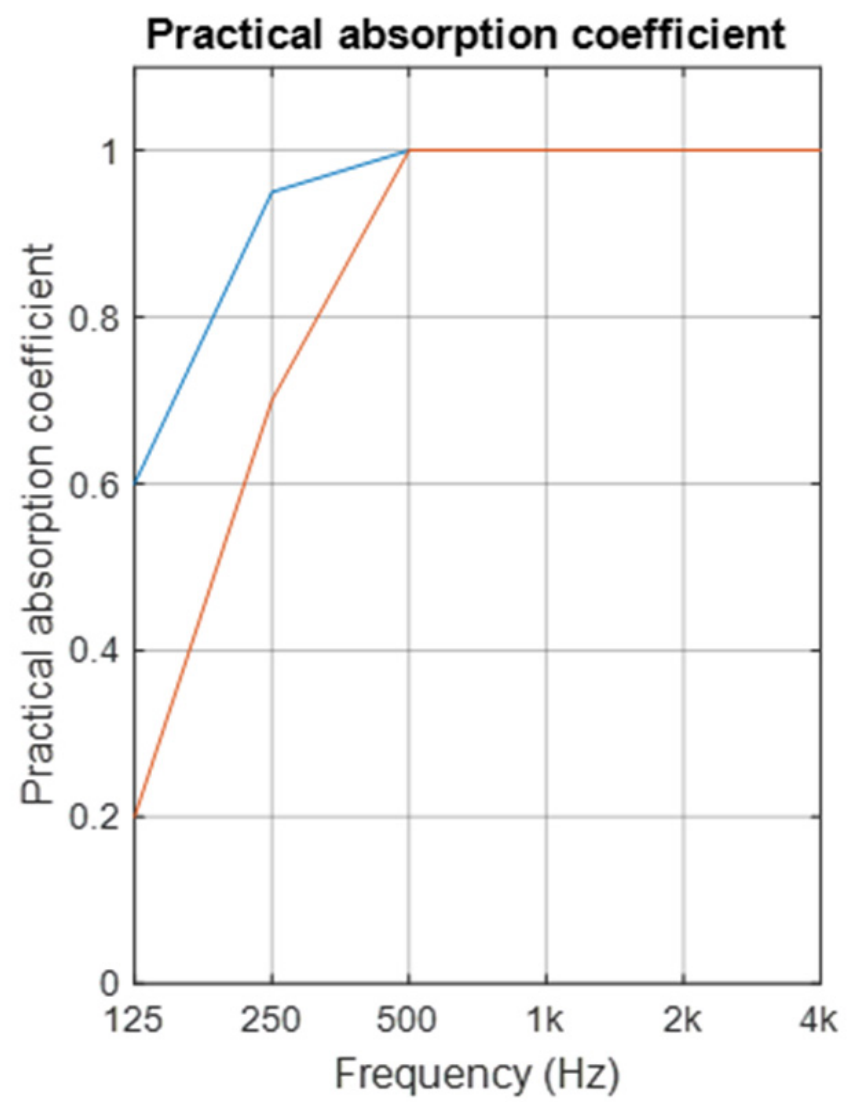

Figure 1. Absorption coefficient for a $40 \mathrm{~mm}$ glass wool product used as absorbing material in the experiments. Blue: ODS $200 \mathrm{~mm}$. Red: ODS $50 \mathrm{~mm}$.

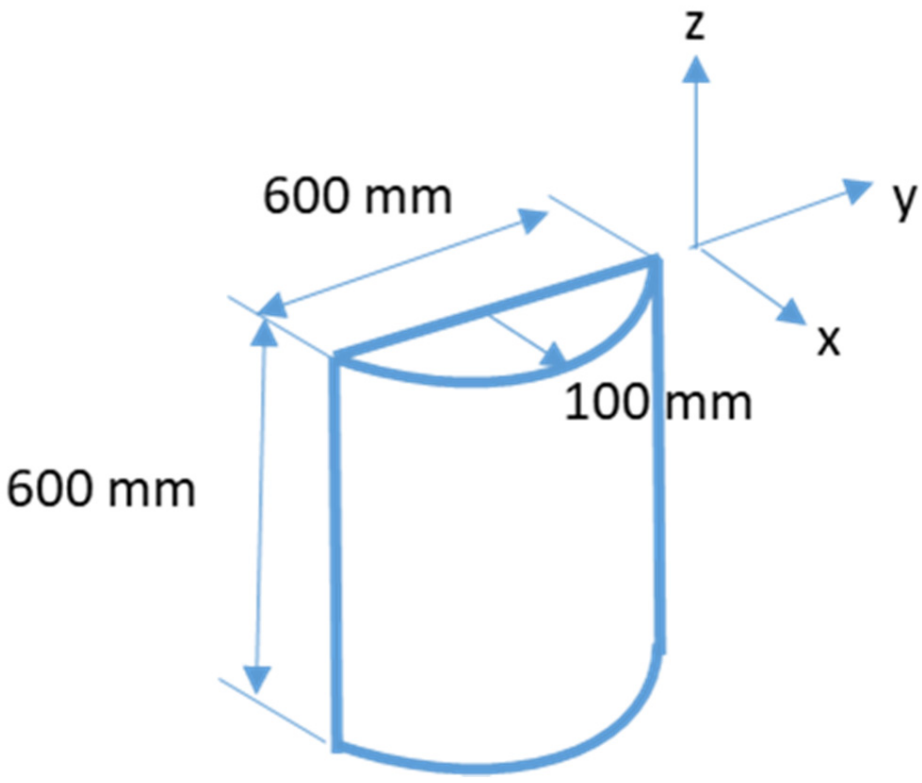

Figure 2. Sketch of diffuser used in the study, horizontally oriented.

Diffusion characteristics were measured in a semi-anechoic chamber. The energy in the reflections was estimated from impulse responses using windowing techniques, excluding the direct sound. The reflections were measured for azimuthal angles $(\theta)$ 0-90 degrees. Figure 3 presents the diffusion characteristics for 500, 2000 and $4000 \mathrm{~Hz}$; assumption of the symmetrical properties has been applied. 


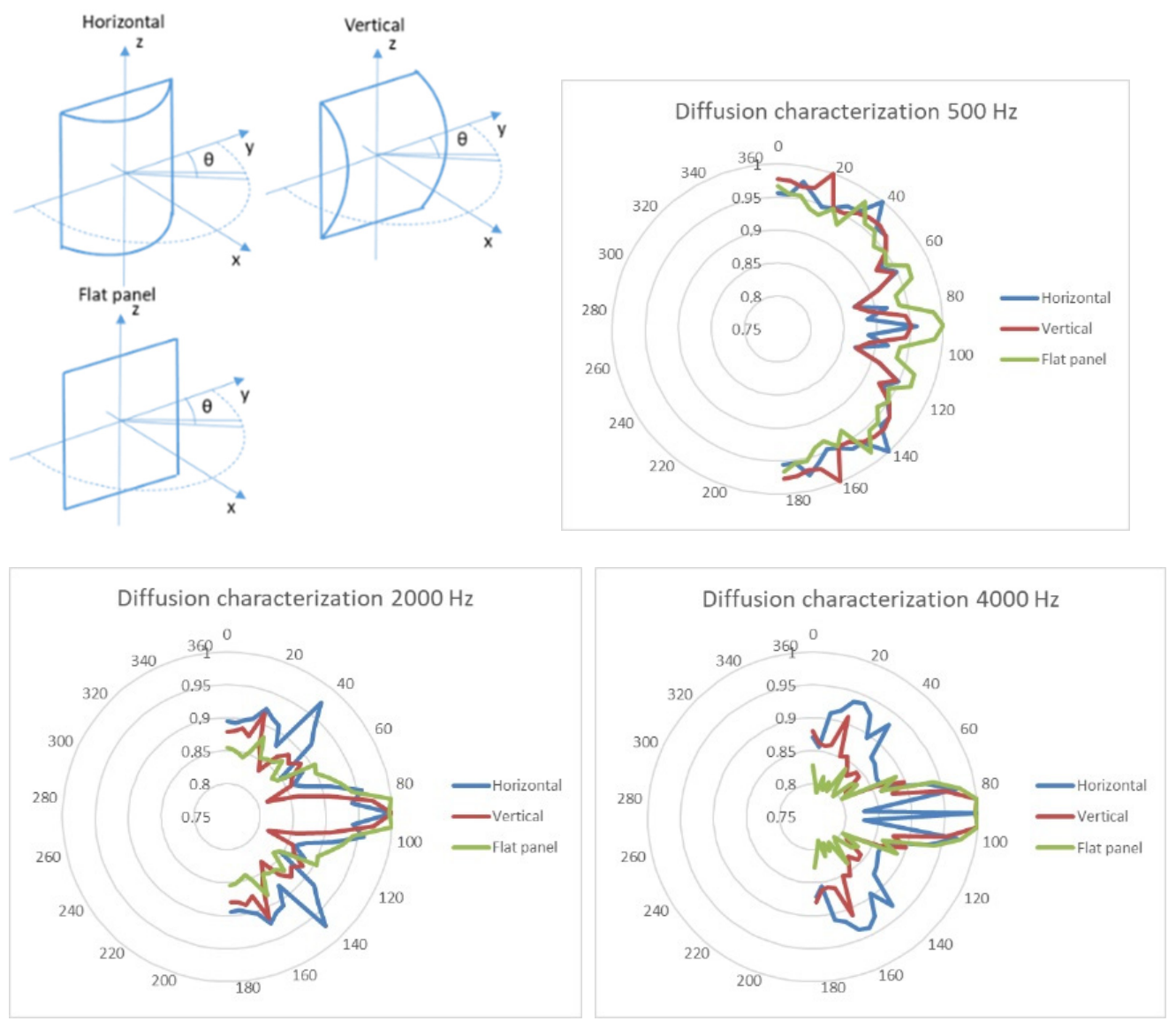

Figure 3. Diffusion characteristics at 500, 2000 and $4000 \mathrm{~Hz}$. Upper left figure shows the orientation of the diffusers relative room coordinates, also visualized in Figures 4 and 5 below.
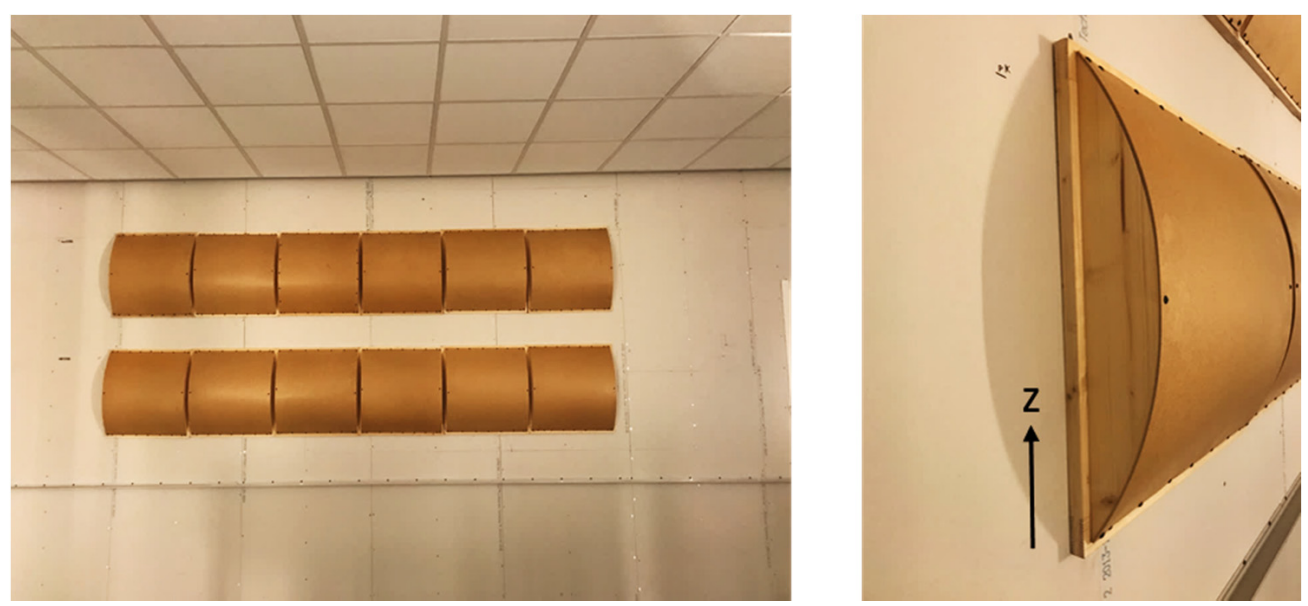

Figure 4. Vertically oriented diffusers; most of reflections will be sent in z-direction.

The diffusers were tested in a vertical and a horizontal orientation. In the vertical position, most sound waves were directed in the z-direction, Figure 4, while for horizontal, most waves were directed in the $\mathrm{x}-\mathrm{y}$ plane, see Figure 5.

\subsection{Mock-Up and Configurations}

The environment where the measurements and recordings were evaluated is a mock-up of a classroom in a laboratory setting. The dimensions of the room were $7.32 \mathrm{~m} \times 7.57 \mathrm{~m} \times 3.50 \mathrm{~m}$, see Figure 6. 

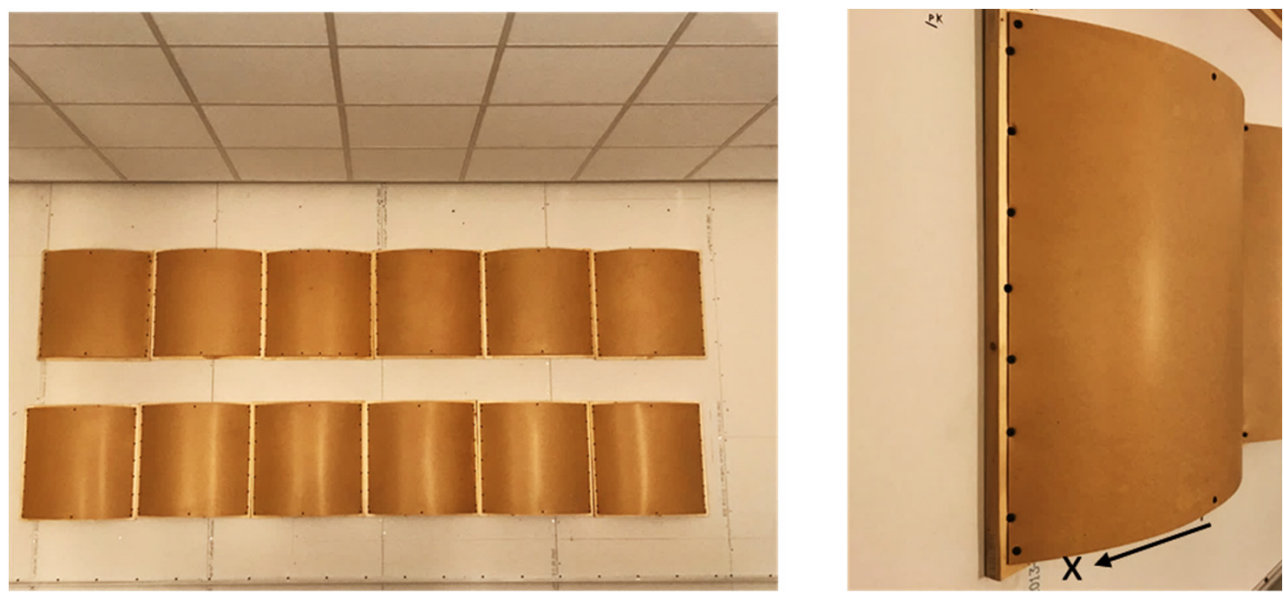

Figure 5. Horizontally oriented diffusers; most of reflections will be sent in $\mathrm{x}$-direction.

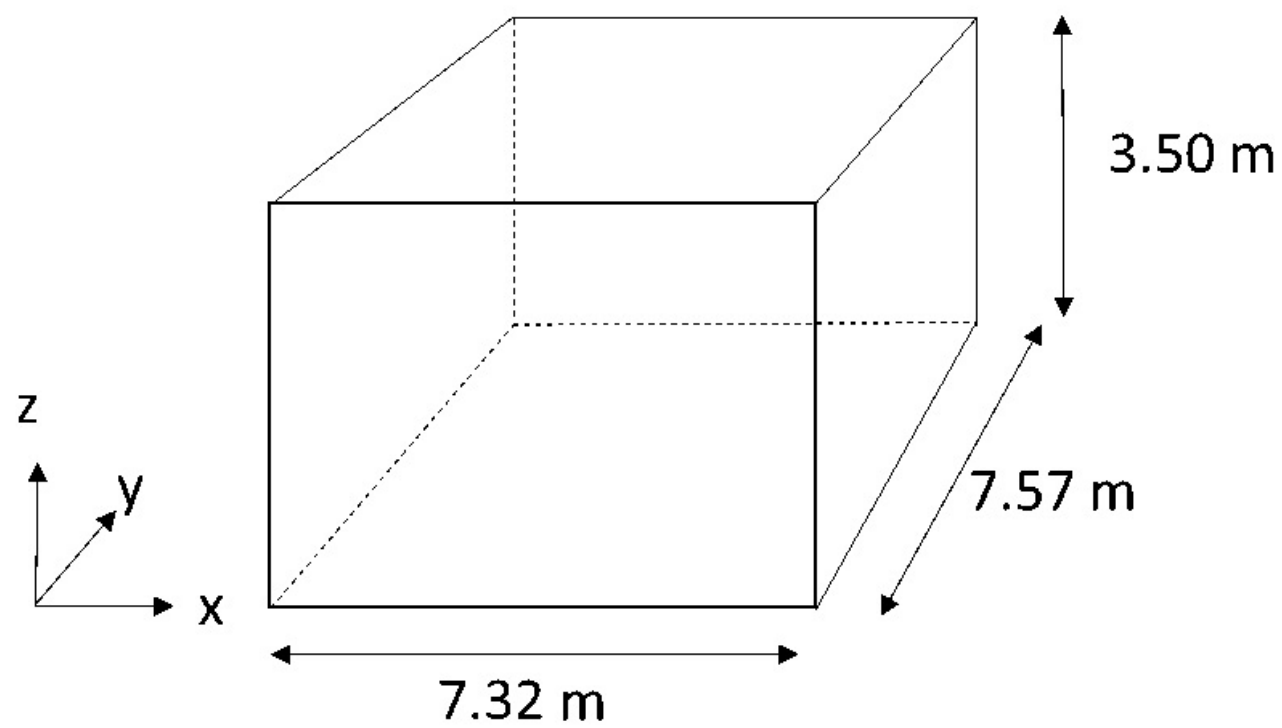

Figure 6. The dimensions of the room used in the experiments: coordinate system where $x$ is the width, $\mathrm{y}$ is the length and $\mathrm{z}$ is the height of the room.

Five different configurations were evaluated. As a baseline, an absorptive ceiling was installed. All configurations were sparsely furnished, with 11 tables and 18 slightly upholstered chairs being used. The room was equipped with a whiteboard, a flipboard and luminaires on the walls, see Figure 7.

The first configuration had only the acoustic ceiling, covering $52 \mathrm{~m}^{2}$, as acoustic treatment. For the second configuration, absorptive tiles were added on two walls, with a total of $9 \mathrm{~m}^{2}$ being covered. In the third and fourth configurations, diffusing elements were used on the walls, vertically and horizontally oriented, respectively. The same placement and coverage areas were used as for the absorptive tiles. The last, fifth, configuration was based on configuration two but with 12 absorbing ceiling tiles replaced by 12 diffusing elements in the source area, i.e., the speaking area, which was covering $4 \mathrm{~m}^{2}$. Abbreviations has been used to describe the configurations, see Table 1. Full description of configurations, see Table 2. Pictures of the configurations are found in Figure 7 for Conf 1, and in Figure 8 for Conf 2-5.

\subsection{Room Acoustic Parameters and Measurements}

The room acoustic parameters evaluated are Sound Strength (G) Equation (1), Speech Clarity $\left(\mathrm{C}_{50}\right)$, Equation (2) and Reverberation Time $\left(\mathrm{T}_{20}\right)$. Measurements were performed using the DIRAC system (DIRAC type 7841, Ver.6.0). G was measured using a constant 
sound power source placed on the floor. An exponential sweep signal was used as excitation for evaluation of $C_{50}$ and $T_{20}$. In the latter, an omnidirectional loudspeaker with dodecahedron geometry was used. The center of the loudspeaker was at $1.55 \mathrm{~m}$ from the floor. An omnidirectional microphone was used as a receiver at $1.20 \mathrm{~m}$ from the floor. Two source positions and seven receiver positions were used; for positions see Figure 9.

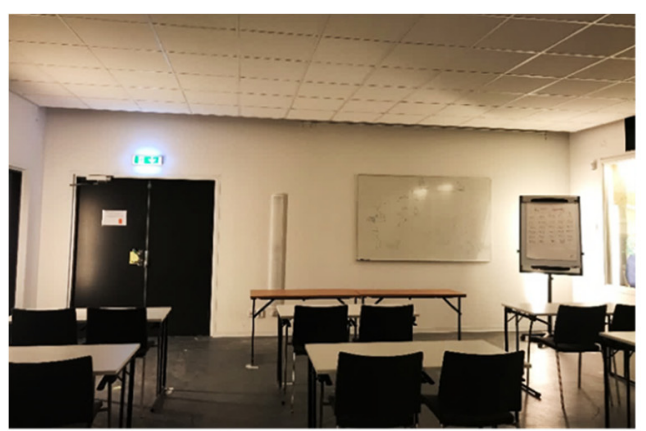

(a)

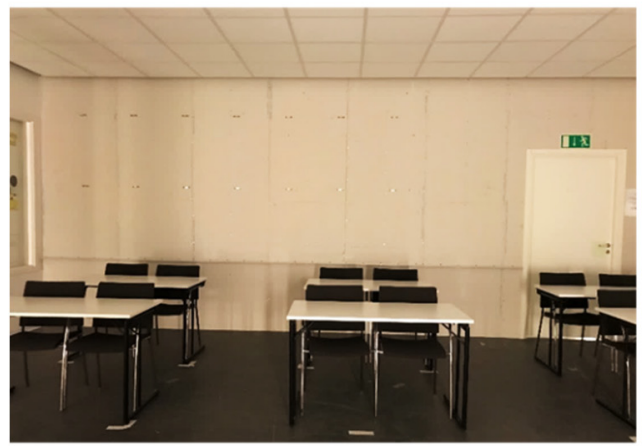

(c)

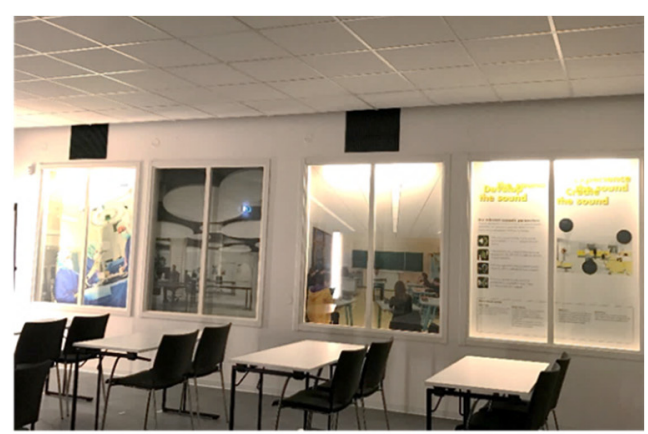

(b)

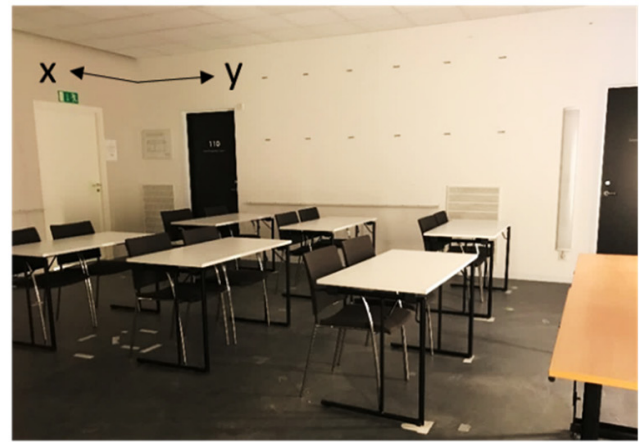

(d)

Figure 7. The classroom with furniture: (a) from the back, (b) from the corner, (c) from the front, (d) from the upper corner, including coordinates for the room.

Table 1. Abbreviations used to describe the configurations.

\begin{tabular}{ccc}
\hline Abbreviation & Description & Comments \\
\hline CA & Ceiling absorptive & XX before any abbreviation \\
WA & Wall absorption & describes the $\mathrm{m}^{2}$ used for the \\
VWD & Vertically oriented wall diffusor & material, e.g., 52 CA stands for \\
HWD & Horizontally oriented wall diffusor & $52 \mathrm{~m}^{2}$ absorptive ceiling \\
\hline F & Furniture & Sparsely furnished \\
\hline
\end{tabular}

Table 2. Description of the configurations used in the test.

\begin{tabular}{|c|c|c|c|c|}
\hline \multicolumn{2}{|r|}{ Configuration } & \multirow{2}{*}{ Ceiling } & \multirow{2}{*}{ Wall Treatment } & \multirow{2}{*}{ Furnished } \\
\hline No & Abbreviation & & & \\
\hline 1 & 52CA_F & $52 \mathrm{~m}^{2}$ absorptive & - & Sparsely \\
\hline 2 & 52CA_9WA_F & $52 \mathrm{~m}^{2}$ absorptive & $9 \mathrm{~m}^{2}$ absorptive tiles distributed on two walls & Sparsely \\
\hline 3 & 52CA_9VWD_F & $52 \mathrm{~m}^{2}$ absorptive & $\begin{array}{c}9 \mathrm{~m}^{2} \text { vertically oriented diffusers distributed } \\
\text { on two walls }\end{array}$ & Sparsely \\
\hline 4 & 52CA_9HWD_F & $52 \mathrm{~m}^{2}$ absorptive & $\begin{array}{l}9 \mathrm{~m}^{2} \text { horizontally oriented diffusers } \\
\text { distributed on two walls }\end{array}$ & Sparsely \\
\hline 5 & 48CA_4CD_9WA_F & $\begin{array}{l}48 \mathrm{~m}^{2} \text { absorptive ceiling, } \\
4 \mathrm{~m}^{2} \text { diffusing elements }\end{array}$ & $9 \mathrm{~m}^{2}$ absorptive tiles distributed on two walls & Sparsely \\
\hline
\end{tabular}



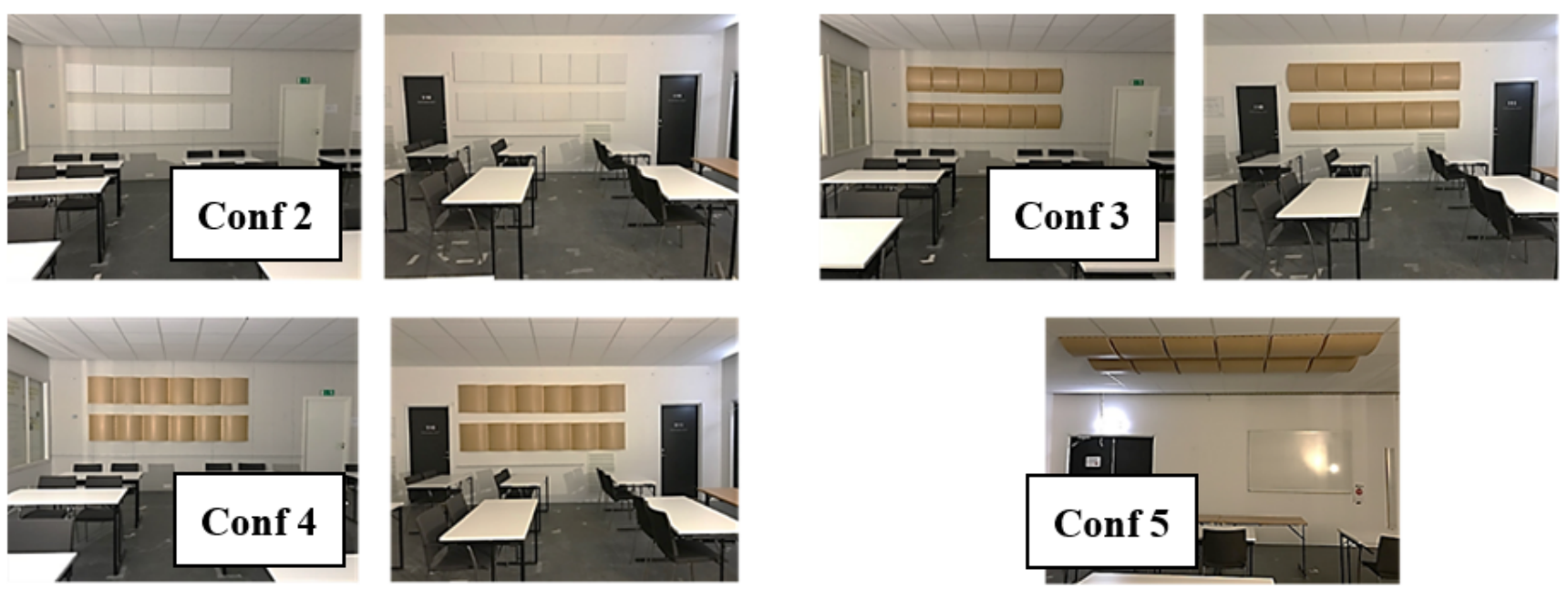

Figure 8. Pictures of configurations. Upper left corner: Conf 2 with absorbing tiles on the walls; Upper right corner: Conf 3, vertically oriented diffusers on the walls; Lower left corner: Conf 4, horizontally oriented diffusers on the walls; Lower right corner: Conf 5, ceiling diffusers, absorbing tiles on the walls as in Conf 2 (upper left corner in this figure).

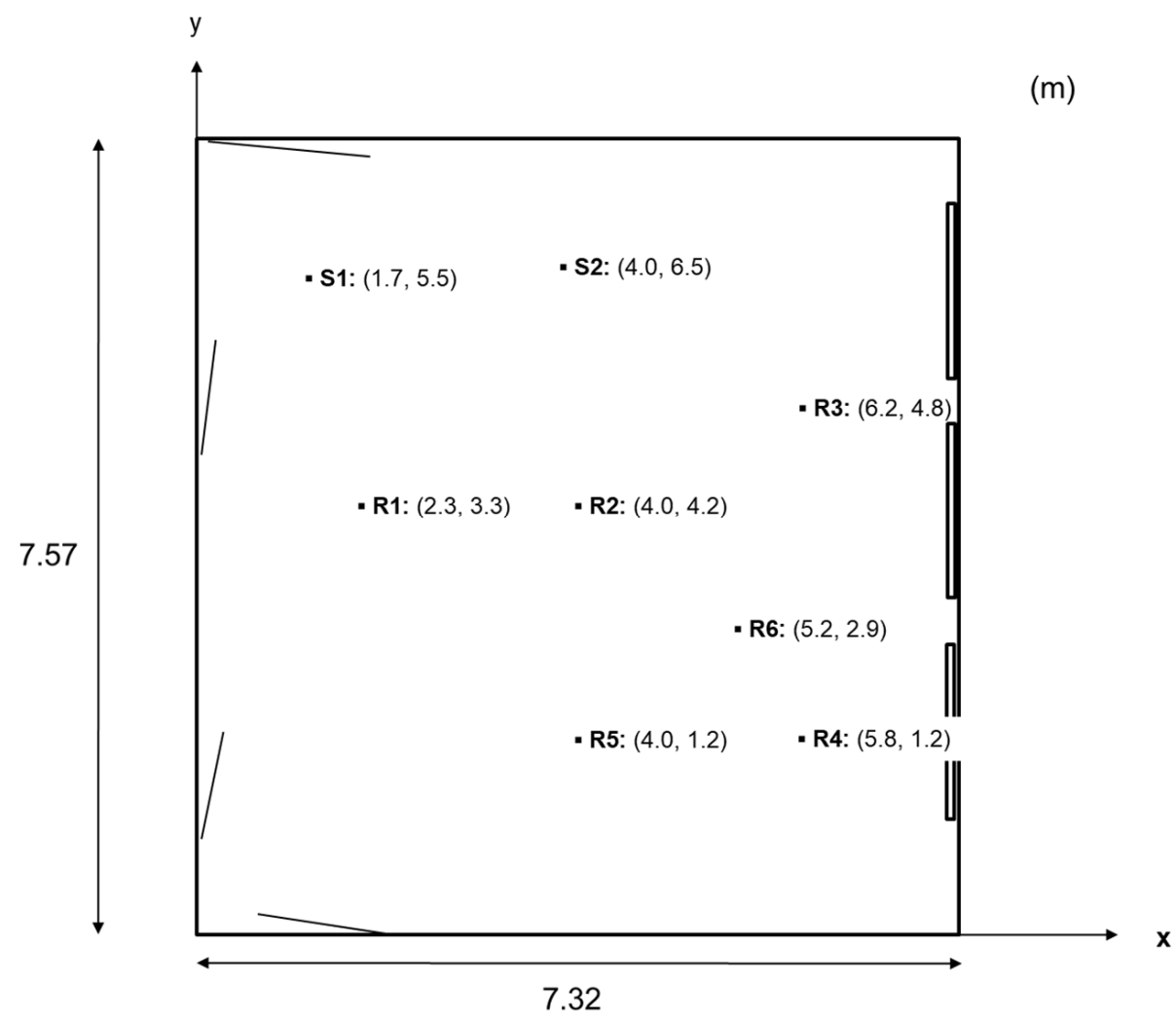

Figure 9. Room dimensions, source positions S1 and S2 and receiver positions R1-R6.

Sound strength $G$ is defined as

$$
G=10 \lg \frac{\int_{0}^{\infty} h^{2}(t) d t}{\int_{0 m s}^{t_{d i r}} h_{10 m}^{2}(t) d t} d B
$$

Speech clarity $\mathrm{C}_{50}$ is defined as

$$
C_{50}=10 \lg \frac{\int_{0}^{50 m s} h^{2}(t) d t}{\int_{50 m s}^{\infty} h^{2}(t) d t} d B
$$


where,

$h(t)$ is the impulse response.

$h_{10 m}$ is the impulse response at $10 \mathrm{~m}$ in a free field.

For both speech clarity and sound strength, the early reflections are included. When evaluating $\mathrm{T}_{20}$, according to ISO $3382-2$, the evaluation interval is $-5 \mathrm{~dB}$ to $-25 \mathrm{~dB}$, given that the early reflections are excluded.

The measurements were performed during the course of one day with stable temperature and humidity conditions. The background noise level was $<30 \mathrm{dBA}$. The repeatability of the measurements was evaluated in a previous article [15] and the uncertainty interval for a 95\% confidence interval is shown in Table 3.

Table 3. Interval of the uncertainty for the room acoustic measurements.

\begin{tabular}{cccc}
\hline & $\mathbf{G}_{\mathbf{a v g}}(\mathbf{d B})$ & $\mathbf{C}_{\mathbf{5 0}, \mathbf{a v g}}(\mathbf{d B})$ & $\mathbf{T}_{\mathbf{2 0} \text {, avg }}$ (s) \\
\hline $125 \mathrm{~Hz}$ & \pm 0.61 & \pm 0.56 & \pm 0.077 \\
$250 \mathrm{~Hz}$ & \pm 0.30 & \pm 0.29 & \pm 0.018 \\
$500 \mathrm{~Hz}$ & \pm 0.40 & \pm 0.29 & \pm 0.010 \\
$1000 \mathrm{~Hz}$ & \pm 0.25 & \pm 0.27 & \pm 0.006 \\
$2000 \mathrm{~Hz}$ & \pm 0.37 & \pm 0.38 & \pm 0.010 \\
$4000 \mathrm{~Hz}$ & \pm 0.36 & \pm 0.36 & \pm 0.008 \\
\hline
\end{tabular}

\subsection{Listening Test}

\subsubsection{Sound Sampling Set-Up}

Material for the listening tests was collected by recording sounds in the same environment described in the previous section. Female speech, sampled in an anechoic chamber, was played from a loudspeaker, type Genelec $8030 \mathrm{~B}$, placed in S2, with the acoustic center at $1.55 \mathrm{~m}$ from the floor. The emitted sound power level was the same for all samplings. Recordings were made with binaural headphones, BHS II (3322) HEAD Acoustics, with calibrated microphones. B2U (3323) HEAD acoustics adapter is used for recording and playback equalization. Each sample lasted 4-6 s and was recorded at a height of $1.20 \mathrm{~m}$ from the floor. Recordings were made in positions R2, R4 and R5. Positions are the same as for the room acoustic measurements, described in Figure 9. Source and headphones can be seen in Figure 10. The headphones used for the recordings were also the playback system in the listening test.

\subsubsection{Test Design}

There is no standard for listening tests in ordinary public rooms. The objective of studies investigating subjective experiences often differs and the design of the test is thereby critical; the test design must relate to the objective of the study and may thereby vary from case to case. However, a common challenge in test design is the risk of bias [37], which must be considered. Aspects of bias can in this case be insights in the study ongoing or preconception. Other risks are lack of concentration, health issues, hearing impairments, duration of the test, whether the questions are adequate and whether the instructions are clear to the participants in the listening jury. Consequently, these aspects have been considered in the design of this listening test, visualized in Figure 11. As regards the duration, the test was designed to enable performance within $20 \mathrm{~min}$. The time needed is related to the ability to maintain concentration. Additionally, in this aspect, the test contained different types of evaluations for the avoidance of monotony. The jury was composed of randomized mix of persons with an age span between 23 to 52 years old. None of the participants had insights into the study. Furthermore, the sounds were randomized. All participants completed training before performing the test.

The test design was evaluated in a pilot study. Five participants with varied experience performed the test and were interviewed on their view of the test. Subsequent modifications were shorter time sequences and clarifications regarding instructions were introduced. The 
judgements of the five participants in this pilot study are excluded from the evaluation presented in the results section of this article.

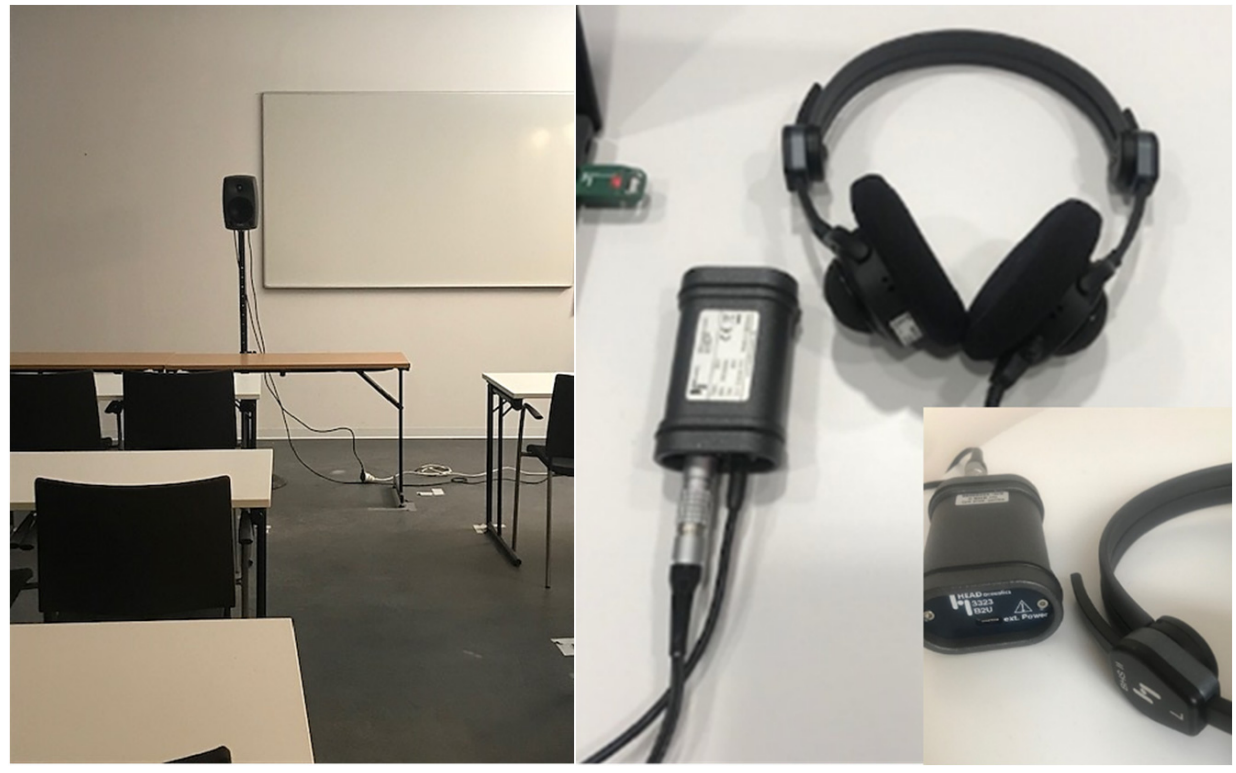

Figure 10. Left: Loudspeaker, Genelec 8030B used as sound source for listening test recordings. The source is placed in position S2. Right: Headphones BHS II and adapter B2U for equalization of recordings and for recordings to listening test. Same headphones are used both for recordings and jury evaluation.

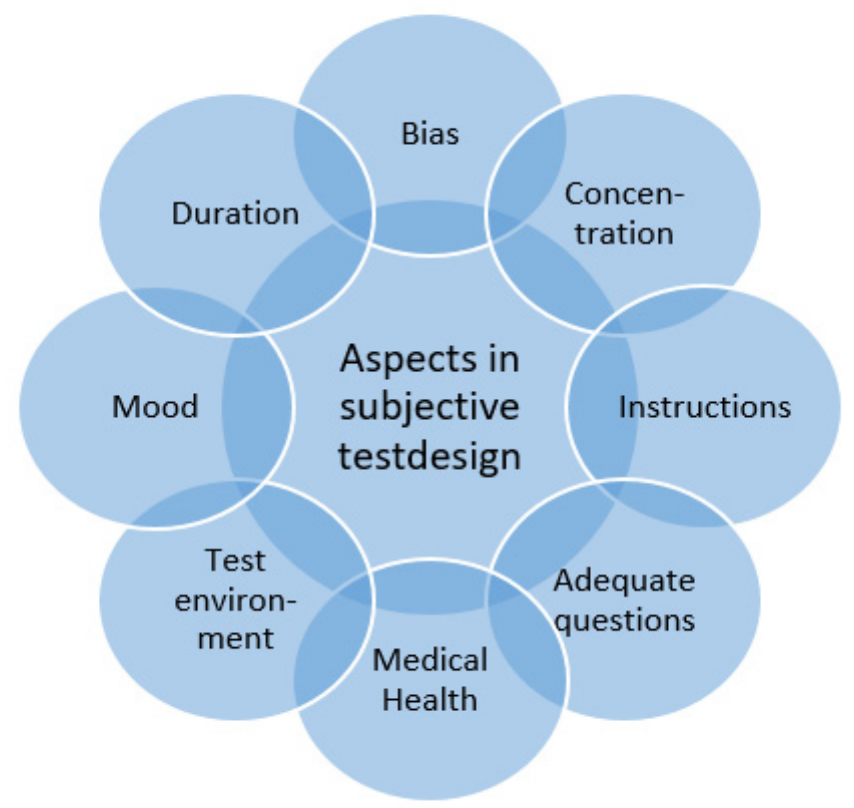

Figure 11. Aspects to be considered in the design of the listening test.

\subsubsection{Performance of Listening Test}

Twenty-nine people participated in the listening test. Fifteen of them were females. The test was made individually; thus, the test took place in the same room for every participant.

The training session contained the test and software instructions. The instructions were available for repetition during the entire listening test. The participants were instructed to make their choice based on their preferences if listening to information or instructions in a classroom environment. The participants were encouraged to make their choices and judgements based on their first impressions. 
In the first part of the test participants answered questions about themselves:

- Age;

- Self-judgement of hearing capability;

- Their mood at the time;

- Previous experience of listening tests;

- Education or particular interest in the area of acoustics, as well as music.

The aim of collecting this data was to have background information if outlier results are identified.

To evaluate whether the listeners experienced differences, pairwise evaluation was made. Two different sound files were presented to the listeners, who considered whether they differed or not. This was repeated for the different combinations of listening positions in Conf 1-3, i.e., absorbent ceiling only, absorbent ceiling with absorbers on the walls, or vertically oriented diffusers on the walls. An equivalent type of judgement was made for the same listening positions but with varied configurations instead, in this case Conf 1-3.

The same procedure was performed for comparison between configurations with vertically and horizontally oriented diffusers, i.e., Conf 3 and 4 , and for comparison of Conf 2 and 5, i.e., the two configurations with wall diffusers, vertically versus horizontally oriented. The set-up of evaluations can be found in Table 4 .

Table 4. Set-up of evaluations, steps 1-3, is evaluation of different positions within one configuration. Steps 4-6 are evaluation of a specific position between different configurations.

\begin{tabular}{|c|c|c|c|}
\hline Step & Object for Evaluation & \multicolumn{2}{|c|}{ Pairwise Sound Judgement } \\
\hline 1 & Difference internally Conf 1 & $\begin{array}{ll}\text { - } & \mathrm{R} 2 / \mathrm{R} 5 \\
\text { - } & \mathrm{R} 2 / \mathrm{R} 4 \\
\text { - } & \mathrm{R} 5 / \mathrm{R} 4\end{array}$ & \\
\hline 2 & Difference internally Conf 2 & $\begin{array}{ll}- & \mathrm{R} 2 / \mathrm{R} 5 \\
\text { - } & \mathrm{R} 2 / \mathrm{R} 4 \\
\text { - } & \mathrm{R} 5 / \mathrm{R} 4\end{array}$ & \\
\hline 3 & Difference internally Conf 3 & $\begin{array}{ll}- & \mathrm{R} 2 / \mathrm{R} 5 \\
\text { - } & \mathrm{R} 2 / \mathrm{R} 4 \\
\text { - } & \mathrm{R} 5 / \mathrm{R} 4\end{array}$ & \\
\hline 4 & Differences for position R2 & $\begin{array}{ll}- & \text { Conf } 1 / \text { Conf } 2 \\
\text { - } & \text { Conf } 1 / \text { Conf } 3 \\
\text { - } & \text { Conf } 2 / \text { Conf } 3\end{array}$ & $\begin{array}{ll}\text { - } & \text { Conf } 3 / \operatorname{Conf} 4 \\
\text { - } & \text { Conf } 2 / \operatorname{Conf} 5\end{array}$ \\
\hline 5 & Differences for position R4 & $\begin{array}{ll}\text { - } & \text { Conf } 1 / \text { Conf } 2 \\
\text { - } & \text { Conf } 1 / \text { Conf } 3 \\
\text { - } & \text { Conf } 2 / \text { Conf } 3\end{array}$ & $\begin{array}{ll}\text { - } & \text { Conf } 3 / \operatorname{Conf} 4 \\
\text { - } & \text { Conf } 2 / \text { Conf } 5\end{array}$ \\
\hline 6 & Differences for position R5 & $\begin{array}{ll}- & \text { Conf } 1 / \text { Conf } 2 \\
\text { - } & \text { Conf } 1 / \text { Conf } 3 \\
\text { - } & \text { Conf } 2 / \text { Conf } 3\end{array}$ & $\begin{array}{ll}\text { - } & \text { Conf } 3 / \operatorname{Conf} 4 \\
\text { - } & \text { Conf } 2 / \operatorname{Conf} 5\end{array}$ \\
\hline
\end{tabular}

An evaluation of the test itself was included in the test. The participants were able to give feedback on whether they had hard time to concentrate and whether the instructions had been clear. The participants judged their experience themselves. A scale $0-10$ were used. Regarding concentration were 0 described as not difficult and 10 as very difficult. For instructions was 0 described as not clear and 10 as totally clear.

The jury test was performed using SQala, Artemi Suite 12.1, HEADacoustics.

\section{Results}

The following chapter presents the results for room acoustics and the listening test. 


\subsection{Room Acoustics}

The room acoustics were investigated as average values, i.e., over the two source positions and seven receiver positions, as well as for the specific receiver positions R2, R4 and R5. In these cases, the source was placed in S2.

Evaluating the average values shows how adding absorptive wall panels (52CA_9WA_F) to the room with absorbent ceiling and furniture (52CA_F) decreases $T_{20}$, mainly at frequencies of $500 \mathrm{~Hz}$ and upwards; at octaves $1000 \mathrm{~Hz}, 2000 \mathrm{~Hz}$ and 4000 the difference was about $0.3 \mathrm{~s}$. $\mathrm{C}_{50}$ changed in the same frequency range, as much as a $3-4 \mathrm{~dB}$ difference at octaves 1000, 2000 and $4000 \mathrm{~Hz}$. For G, addition of wall panels gave a lower value of 0.5-1.0 dB as early as at octave of $250 \mathrm{~Hz}$, where the furniture has absorption properties.

Replacing the absorptive tiles on the walls (52CA_9WA_F) with vertically oriented diffusers (52CA_9VWD_F) resulted in slightly higher $\mathrm{T}_{20}$ and lower $\mathrm{C}_{50}, 1-2 \mathrm{~dB}$, in the higher frequency range. Opposite behavior is seen at the lower octaves $125-250 \mathrm{~Hz}$. The diffusers are designed to operate as resonance absorbers in this frequency range, explaining this change. The effect of the resonance absorber is also seen in G. For the higher frequencies, it can be seen how the diffusers give higher $\mathrm{G}$ compared to configuration with absorbers.

In the next configuration, the wall diffusers were changed to a horizontal orientation. This change made no difference to $G$, meaning this value is independent of diffuser orientation; the absorption properties do not differ. However, for $\mathrm{T}_{20}$ and $\mathrm{C}_{50}$, changes were seen. Comparing configurations with different diffuser orientations gives a difference of approximately $1.5 \mathrm{~dB}$ in speech clarity, with lower values for horizontally oriented diffusers. $\mathrm{T}_{20}$ increases with horizontally oriented diffusers. The differences previously described are valid for the frequency range 1000-4000 Hz. In the lower frequency range, where the elements' main function is as resonance absorption, the room acoustic results are similar for the two configurations 3 and 4 . It should be noted that the configuration with horizontally oriented diffusers still has an effect on the room acoustic parameters when compared to configuration with no acoustic treatment on the walls (Conf 1 ).

Replacing 12 absorptive ceiling tiles with diffusing elements, Conf 5 (48CA_4CD_9WA_F), in configuration with absorption panels on the walls, Conf 2 (52CA_9WA_F), gives on average a small decrease in $\mathrm{T}_{20} . \mathrm{C}_{50}$ is on average similar for these two configurations. Slightly higher values are seen for G. Average results can be seen in Figure 12.

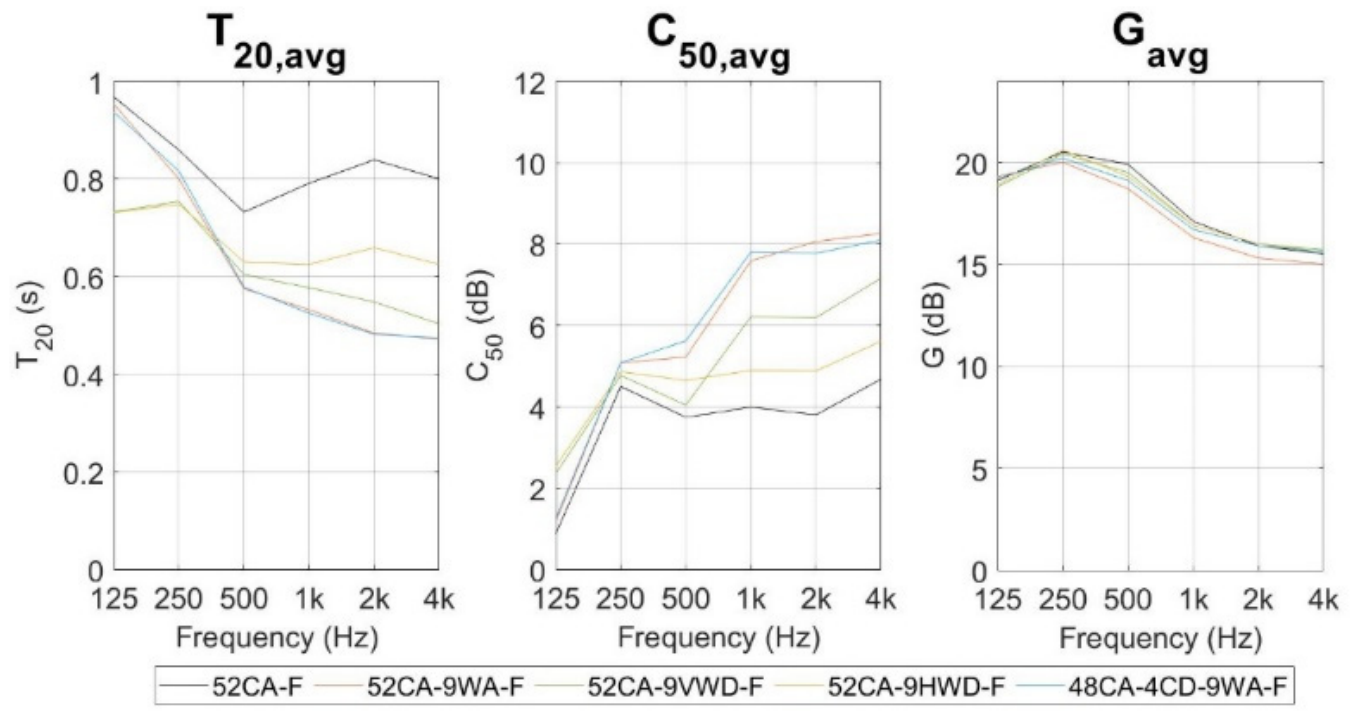

Figure 12. Room acoustic parameters for the five different configurations. Results presented in these graphs are average values from two source positions and seven receiver points, i.e., in total 14 measurements per configuration. 
Focusing on internal differences for Conf $1-3$ shows small variations in $\mathrm{T}_{20}$ values in each configuration. However, the smallest variation is in Conf 2, absorbing tiles on the walls.

As regards $C_{50}$ for the same configurations and receiver positions, variations are apparent. The focus of the evaluation is within the higher frequency range. In terms of $\mathrm{dB}$, the variations are smaller for Conf 2 and 3, i.e., configurations with acoustic treatment on the walls. It should also be noted that the variation between positions R4 and R5 is smallest for Conf 3, vertically oriented diffusers on the walls.

Looking into the $\mathrm{G}$ values, variations are slightly greater for the configuration with wall absorbers. Conf 1 and 3 behave similarly as regards variation. However, all three configurations have small variations between the two positions at the back of the room, R4 and R5. The results for internal differences in the Conf 1-3 are shown in Figure 13.

Comparisons between specific positions using vertically or horizontally oriented diffusers, Conf 3 and 4, show, in the higher frequency range, higher $T_{20}$ values and lower $\mathrm{C}_{50}$ values in all positions for Conf 4 . With regard to $C_{50}$, the largest variant is seen in position R5, the difference being $3.2 \mathrm{~dB}$. G is similar when comparing the same positions for the two configurations with diffusers on the walls.

In addition, the question has been investigated of whether the room acoustic parameters differ for configuration with ceiling diffusers replacing 12 absorptive tiles. The configuration for this comparison includes absorptive tiles on the walls, i.e., Conf 2 and 5. As regards $T_{20}$ and $G$, slightly lower values are seen for Conf 2. Regarding $C_{50}$, the configuration with ceiling diffusers gives an increase at $2000 \mathrm{~Hz}$. This increase is around $1 \mathrm{~dB}$ in the positions further away from the source, R4 and R5. Room acoustic parameters for specific receiver positions (R2, R4 and R5), all configurations, are shown in Figure 14.

All room acoustic data can be found in Appendix A.

\subsection{Listening Test}

The average age of the 29 participants ( 15 females, 14 males) performing the listening test was 37 years. Regarding the question of whether it had been difficult to concentrate, the average value was 3 (scale $0-10$ where $0=$ not difficult, $10=$ very difficult). On the question as to how clear the instructions were, the average answer was 10 (scale $0-10,0=$ not clear, $10=$ totally clear). Three participants reported some type of hearing impairment. No one reported medical illness. Most participants described their mood with positive words such as enthusiastic, alert and curious. A couple of participants reported feelings of stress and tiredness. No significant differences in the answers could be found due to any of these aspects. In some cases, are deviating responses reported. These results have not affected the main outcome in the analysis of this study. The deviating responses were reported from different jury members and no specific outlier in the jury group could be identified. Deviating responses could not be related to the concertation ability or instruction clarity, neither to the responses on health. Thereby are all responses included in the results presented in coming paragraphs.

In the first part of the listening test, internal differences in configurations 1-3 were evaluated. On the question of whether the participants could identify a difference between different positions, differences between positions R2 and R5 as well as between R2 and R4 were clearly observed for all three configurations. Regarding a comparison of positions R4 and R5, 41\% judged it to be the same within Conf 1 . For Conf 3, this value was higher, with $48 \%$ considering it to be same. For Conf 2 , the percentage judging the two positions to be the same was lower, 28\%. These results can be found in Figure 15.

When asking participants whether they could observe a difference between different configurations, the positions are the same, with regard to configurations 1-3 the majority could observe a difference in all positions when comparing configurations 1 and 2. For position R4, however, 24\% deemed the sounds to be similar. When comparing Conf 1 and 3, the percentage observing different values in R2 was $24 \%$, in R4 28\% and, in R5, the majority, $62 \%$ judged it to sound the same. Comparing Conf 2 and 3 showed that $90 \%$ thought it 
sounded the same in position R2, in R4 72\% judged it to be the same and, in R5, this value was 55\%. The results can be seen in Figure 16.
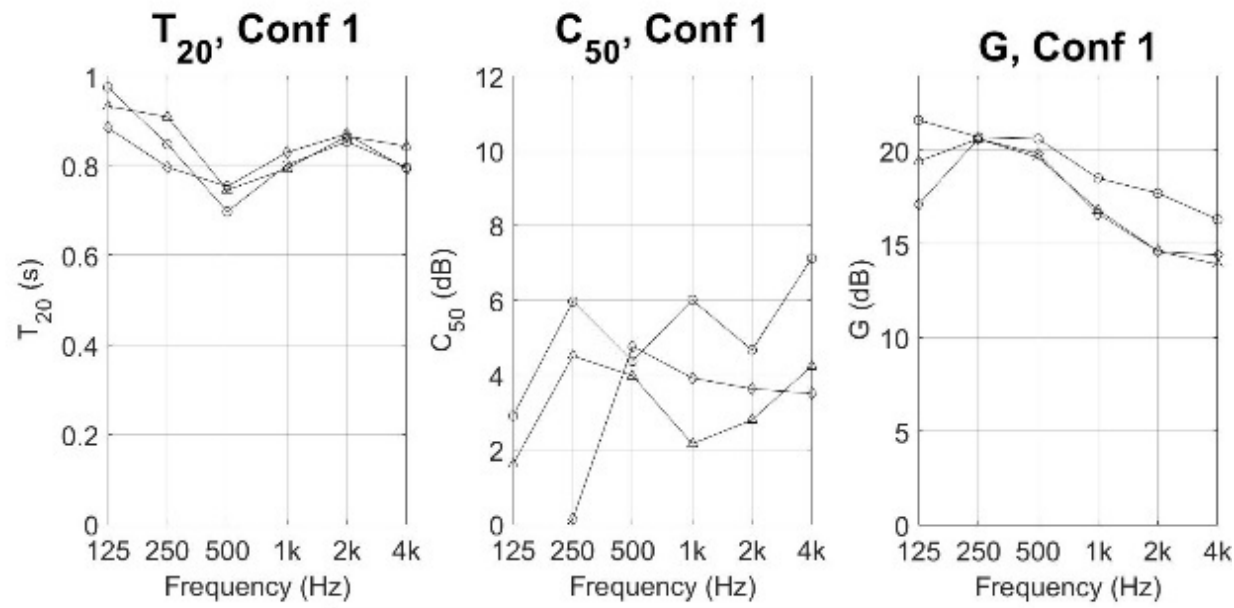

$\rightarrow 52 \mathrm{CA}-\mathrm{F}, \mathrm{S} 2, \mathrm{R} 2 \multimap 52 \mathrm{CA}-\mathrm{F}, \mathrm{S} 2, \mathrm{R} 4 \rightarrow 52 \mathrm{CA}-\mathrm{F}, \mathrm{S} 2, \mathrm{R} 5$
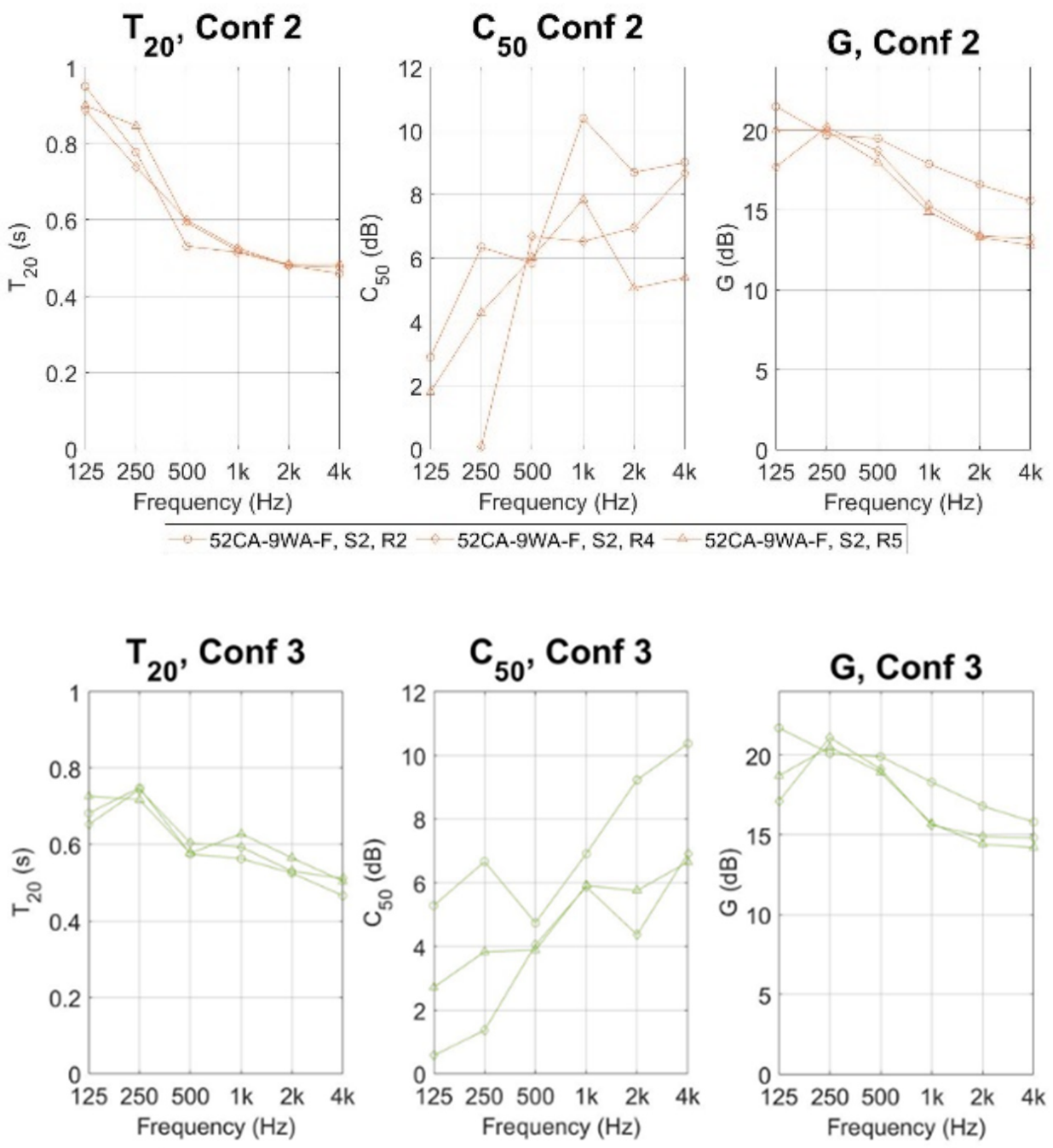

52CA-9VWD-F, S2, R2 $\multimap$ 52CA-9VWD-F, S2, R4 52CA-9WWD-F, S2, R5

Figure 13. Results room acoustic parameters for three different positions R2, R4, R5 in Conf 1, Conf 2 and Conf 3. 

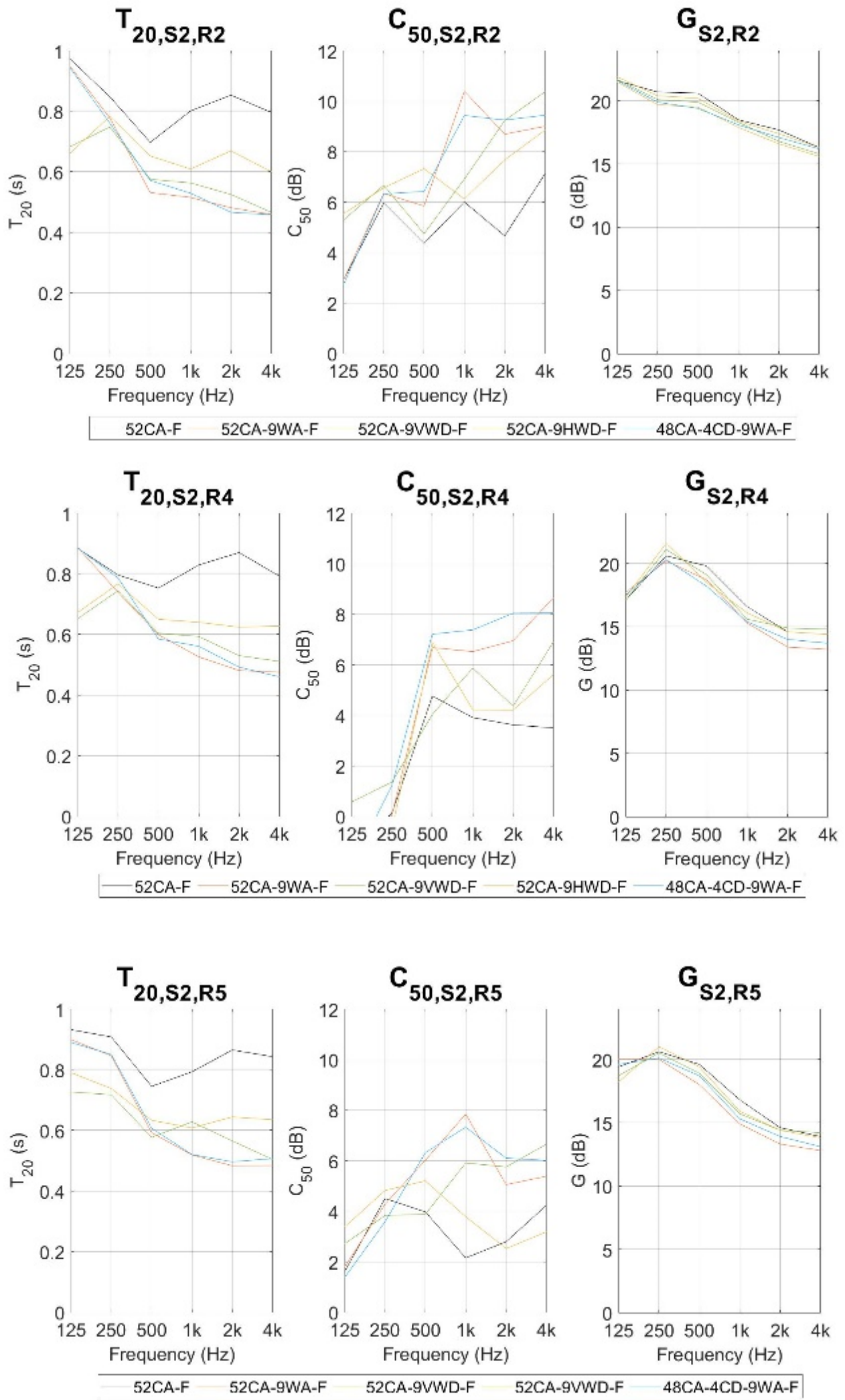

Figure 14. Room acoustic parameters in position R2, R4 and R5 for all configurations.

Comparing the two configurations were vertically and horizontally oriented diffusers was used showed that the majority did not observe a difference between the configurations. In position R4, only $6.9 \%$ observed a difference, in R4 $21 \%$ observed a difference and in position R5 24\% observed a difference. The results can be seen in Figure 17. 


\section{Comparison of internal differneces in Conf 1,2 and 3.}

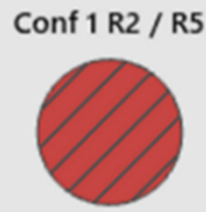

$100,0 \%$

Conf 2 R2 / R5

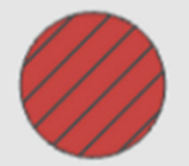

$100,0 \%$
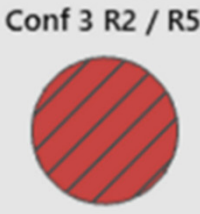

100,096

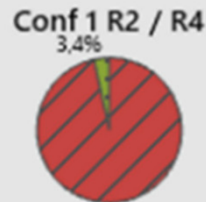

$96,6 \%$

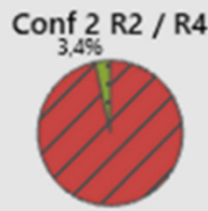

$96,6 \%$

Conf 3 R2 / R4

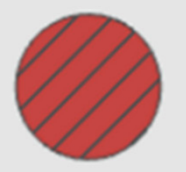

$100,0 \%$

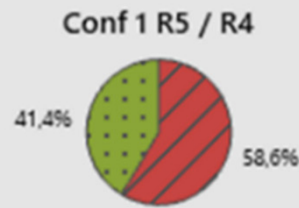

Category

Different

Same

Figure 15. Result on perception of whether participants experienced the sound to be same or different for different positions within one configuration. Conf 1 in the first row, Conf 2 in second row and Conf 3 in third row.

\section{Differences in positions R2, R4 and R5 between Conf 1, 2 and 3}

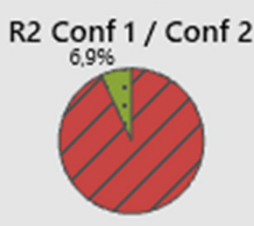

$93.1 \%$

R4 Conf 1 / Conf 2

$24,19 \%$

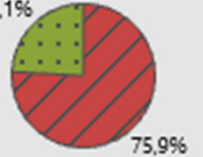

R5 Conf 1 / Conf 2

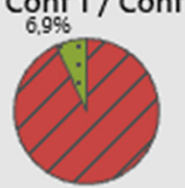

93.196

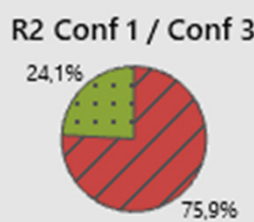

R4 Conf 1 / Conf 3

27,696

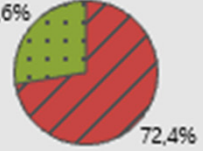

R5 Conf 1 / Conf 3

$62,1 \%$

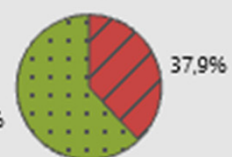

R2 Conf 2 / Conf 3

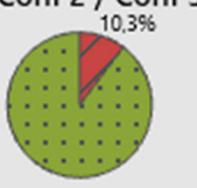

$89,7 \%$

R4 Conf 2 / Conf 3

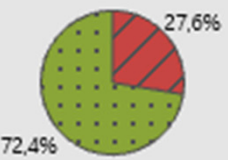

R5 Conf 2 / Conf 3

55,296

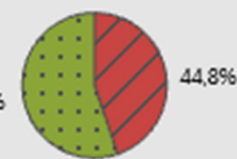

Figure 16. Differences between different configuration for certain positions. First row position R2, second row positions $\mathrm{R} 4$ and third row position R5.

Comparison of Conf 2 and 5, meaning the effect of ceiling diffusers, shows that the majority judged the sound to be the same; however, $38 \%$ thought it sounded different in position R5 and $24 \%$ thought it sounded different in position R4. Results can be seen in Figure 17. 


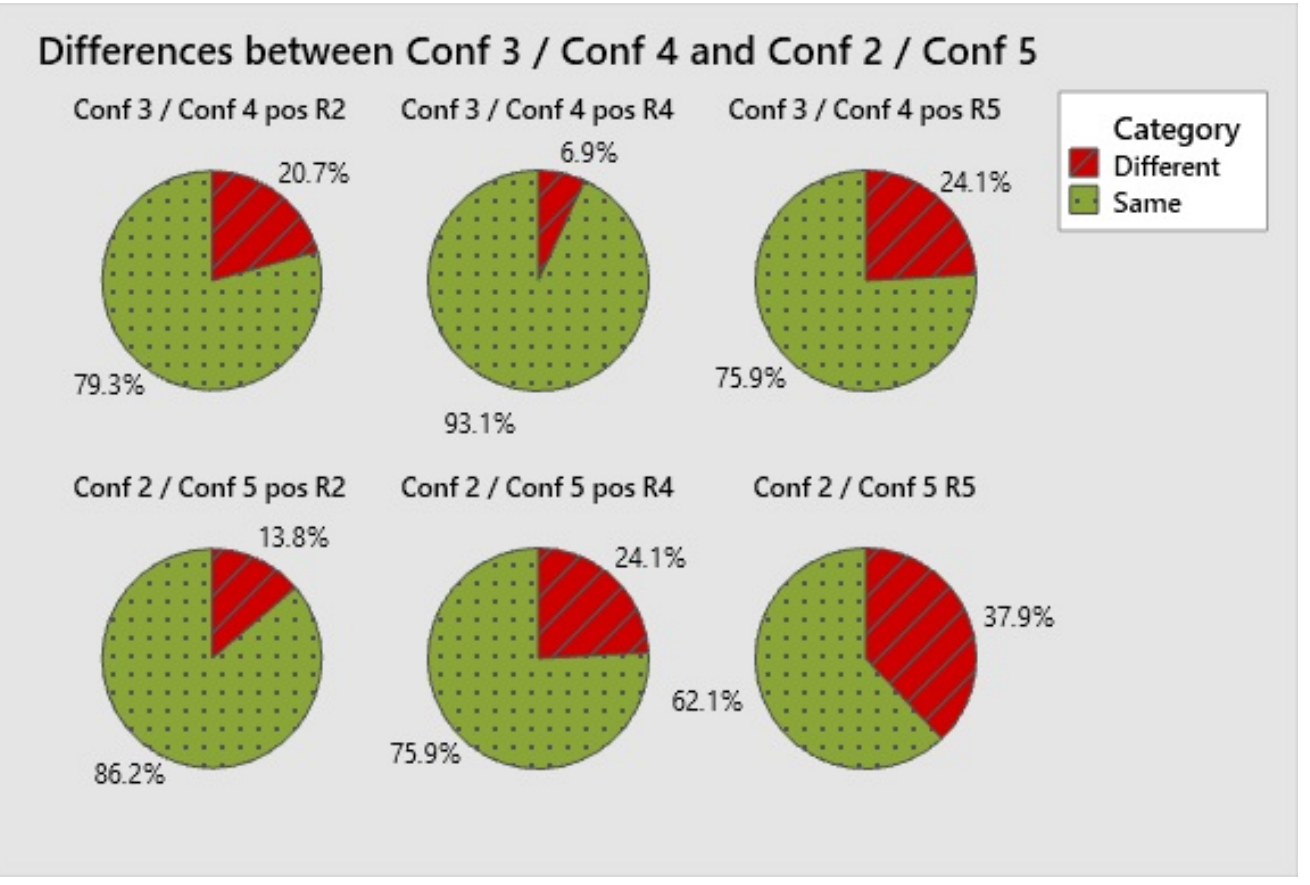

Figure 17. First row: the difference between configurations with vertically oriented diffusers, Conf 3 , and horizontally oriented diffusers, Conf 4, for positions R2, R4 and R5. Second row: the difference between configurations with only absorbent ceiling, Conf 2, and with ceiling diffusers, Conf 5, for positions R2, R4 and R5.

\section{Discussion}

Looking at the internal differences in configurations 1, 2 and 3, participants perceived the sound to be different between R2 and R5 in all cases. Additionally, between R2 and $\mathrm{R} 4$, the majority perceived a difference. However, regarding a comparison between R4 and R5, the participants deemed to a greater extent the two positions to be the same for Conf 1 and 3, i.e., where walls where empty or covered with diffusers. Comparing the room acoustics in the positions R4 and R5 for Conf 2, i.e., when people experienced a difference, was $\mathrm{C}_{50}$ the parameter that differs. The difference was at octaves $2000 \mathrm{~Hz}$ and $4000 \mathrm{~Hz}$, the difference was 2-3 dB. Looking at the same positions, R4 and R5, for Conf 1 and 3 , for which more people experienced sound to be more similar was the difference in $\mathrm{C}_{50}$ smaller.

Comparing sounds in one position but for different configurations, $90 \%$ judged that the sounds for Conf 2 and 3 were the same in position R2. As regards room acoustic parameters we mainly see a difference in $\mathrm{T}_{20}$, for the low frequencies. As people answered that they could not experience a difference, we can say that this difference in $T_{20}$ is not enough to obtain a subjective difference. It should be noted that the sound source in this case was a female voice. A male voice may contain higher ratio of lower frequencies. For such situation can low frequency absorption give other results in perception.

Investigating the same configurations, 2 and 3, in position R4, differences are apparent in room acoustic parameters in the higher frequency range. Speech clarity differs by about $1 \mathrm{~dB}$, reverberation time by $0.05 \mathrm{~s}$ and sound strength by $2 \mathrm{~dB}$ in octaves 2000 and $4000 \mathrm{~Hz}$. As regards this position, still $72 \%$ deeming it to be the same. The differences just mentioned seems thereby not to be enough to significantly experience a difference in perception of speech. Continuing to study the same configurations, i.e., Conf 2 and 3 in the position $\mathrm{R} 5$, the majority of the participants, $55 \%$, judged the two configurations to be the same. The reverberation time differs slightly more at the high frequencies. The $\mathrm{C}_{50}$ shows irregularities in its pattern for this position, but differences of about $1.5 \mathrm{~dB}$ between the 
two configurations are seen for this parameter in the higher frequency range. The sound strength differs slightly less at $2000-4000 \mathrm{~Hz}$, but slightly more at $1000 \mathrm{~Hz}$.

This evaluation indicates that the difference needed to subjectively experience a variation has in this study been higher than typical values for performance spaces in 3382-1 where JND for $\mathrm{C}_{50}$ and $\mathrm{G}$ is $1 \mathrm{~dB}$. Furthermore, can we see an importance of looking separately into the different frequencies.

Evaluating the results for the previously discussed position R5 for Conf 1 and 3 gives an opposite indication. The subjective test showed that the majority considered the sounds to be the same; however, the room acoustic parameters $T_{20}$ and $C_{50}$ differ more in the same frequency range than for previously discussed configurations. For $\mathrm{C}_{50}$ the difference is 2.4-3.8 for the frequency range $1000-4000 \mathrm{~Hz}$, with the difference in $\mathrm{T}_{20}$ being $0.2-0.3 \mathrm{~s}$ for the same frequency range. This implies that the subjective sound image goes beyond these parameters and additional descriptors are needed for a full and appropriate description of how people experience sounds.

Evaluation of the configuration using vertically, or horizontally oriented diffusers shows that the majority perceive the sounds to be the same. The greatest percentage of participants judging "different" was found in position R5, 24\%. In this position, the largest differences in $C_{50}$ and $T_{20}$ are found. For $C_{50}$, the difference at $2000 \mathrm{~Hz}$ and $4000 \mathrm{~Hz}$ is about $3 \mathrm{~dB}$ and $\mathrm{T}_{20} 0.08-0.10 \mathrm{~s}$. G has similar values for these two configurations. This further reinforces the interpretation above, that the difference between these parameters must be greater than is recommended for performance spaces and that the subjective sound image must be considered.

Comparing the effect of ceiling diffusers showed that majority of the participants judged the two configurations, Conf 2 and 5, to be similar. The position where most participants found a difference was $\mathrm{R} 5$. The parameter differing in this position was mainly $\mathrm{C}_{50}$, but the difference is lower than was required for the participants to observe a difference in the other evaluations in this study. A reason for this can be the different subjective sound image that the diffuser creates compared to absorptive panels.

Development of how to describe this sound image is needed. Such development can include further studies of the relation between perceived characteristics of sound to different room acoustic parameters. Additional room acoustic parameters may be considered, furthermore could the measurement technics be considered.

\section{Conclusions}

The evaluation in this study shows that it is important to not only consider average values but also specific positions in the room acoustic design of ordinary rooms. It also shows that greater differences in room acoustic parameters are needed for these types of environments than what is described as just noticeable differences for performance spaces in ISO 3382-1. Furthermore, the evaluation shows that greater differences are needed in the low frequency range compared to the high frequency range. This can be explained by people's lower hearing sensitivity at lower frequencies. Furthermore, a female voice was used in the study, which cannot produce as many low frequencies as a male voice can. The room acoustic parameters measured could not fully explain all the outcomes from the perception evaluation. An important interpretation arising from this study is that it is essential to take the subjective part of the sound image into consideration in the room acoustic design of ordinary rooms.

Author Contributions: Writing-Original Draft Preparation: E.A.; Experiments-Design, Accomplishment and Analysis, E.A.; Writing—Review and Editing, E.A.; Review and Supervision, E.N., O.J.I.K. and D.B.H. All authors have read and agreed to the published version of the manuscript.

Funding: This research received no external funding.

Institutional Review Board Statement: Ethical review and approval were waived for this study. All participants were of legal age. All participants agree to publication of results obtained from the study. All results are decoded. Individual results cannot be tracked. 
Informed Consent Statement: Informed consent was obtained from all subjects involved in the study.

Data Availability Statement: The data presented in this study are available on request from the corresponding author.

Acknowledgments: The authors are grateful for the involvement and positive approach of the Ecophon employees who volunteered for the listening test, especially as this was performed under the special circumstances due to the pandemic. We also want to thank Ecophon R\&D and Innovation for providing material, laboratory facilities and equipment. Thanks!

Conflicts of Interest: The authors declare no conflict of interest.

\section{Appendix A}

Data room acoustic measurements.

\section{References}

1. Barron, M.; Lee, L.J. Energy relations in concert auditoriums. I. J. Acoust. Soc. Am. 1988, 84, 618-628. [CrossRef]

2. Barron, M. Theory and measurement of early, late and total sound levels in rooms. J. Acoust. Soc. Am. 2015, 137, 3087-3098. [CrossRef] [PubMed]

3. Beranek, L. The sound strength parameter $\mathrm{G}$ and its importance in evaluating and planning the acoustics of halls for music. J. Acoust. Soc. Am. 2011, 129, 3020-3026. [CrossRef] [PubMed]

4. Svensk Standard Ss-En Iso 3382-1:2009; Swedish Standards Institute: Stockholm, Sweden, 2009.

5. Sato, H.; Bradley, J.S. Evaluation of acoustical conditions for speech communication in working elementary school classrooms. J. Acoust. Soc. Am. 2008, 123, 2064-2077. [CrossRef]

6. Åhlander, V.L.; Rydell, R.; Löfqvist, A. Speaker's Comfort in Teaching Environments: Voice Problems in Swedish Teaching Staff. J. Voice 2011, 25, 430-440. [CrossRef] [PubMed]

7. Brunskog, J.; Gade, A.C.; Bellester, G.P.; Calbo, L.R. Increase in voice level and speaker comfort in lecture rooms. J. Acoust. Soc. Am. 2009, 125, 2072-2082. [CrossRef] [PubMed]

8. Pelegrín-García, D.; Brunskog, J.; Lyberg-Åhlander, V.; Löfqvist, A. Measurement and prediction of voice support and room gain in school classrooms. J. Acoust. Soc. Am. 2012, 131, 194-204. [CrossRef] [PubMed]

9. Pelegrín-García, D.; Brunskog, J. Speakers' comfort and voice level variation in classrooms: Laboratory research. J. Acoust. Soc. Am. 2012, 132, 249-260. [CrossRef] [PubMed]

10. Lochner, J.; Burger, J. The influence of reflections on auditorium acoustics. J. Sound Vib. 1964, 1, 426-454. [CrossRef]

11. Bradley, J.S.; Sato, H.; Picard, M. On the importance of early reflections for speech in rooms. J. Acoust. Soc. Am. 2003, 113, 3233-3244. [CrossRef]

12. Bradley, J.S.; Reich, R.D.; Norcross, S.G. On the combined effects of signal-to-noise ratio and room acoustics on speech intelligibility. J. Acoust. Soc. Am. 1999, 106, 1820-1828. [CrossRef]

13. Choi, Y.-J. An Optimum Combination of Absorptive and Diffusing Treatments for Classroom Acoustic Design. Build. Acoust. 2014, 21, 175-179. [CrossRef]

14. Choi, Y.-J. The Application of Diffusers for Classroom Acoustical Design. Noise Vib. Worldw. 2014, 45, 8-16. [CrossRef]

15. Arvidsson, E.; Nilsson, E.; Hagberg, D.B.; Karlsson, O.J.I. The Effect on Room Acoustical Parameters Using a Combination of Absorbers and Diffusers-An Experimental Study in a Classroom. Acoustics 2020, 2, 505-523. [CrossRef]

16. DIN 18041:2016-3. Acoustic Quality in Rooms-Specifications and Instructions for the Room Acosutic Design; Deutsches Institut für Normung e., V.: Berlin, Germany, 2016.

17. UNI 11532-2. Internal Acoustical Characteristics of Confined Spaces-Design Methods and Evaluation Techniques-Part 2 Educational Sector; UNI: Milan, Italy, 2020.

18. Azad, H.; Meyer, J.; Siebein, G.; Lokki, T. The Effects of Adding Pyramidal and Convex Diffusers on Room Acoustic Parameters in a Small Non-Diffuse Room. Acoustics 2019, 1, 618-643. [CrossRef]

19. Cucharero, J.; Hänninen, T.; Lokki, T. Influence of Sound-Absorbing Material Placement on Room Acoustical Parameters. Acoustics 2019, 1, 644-660. [CrossRef]

20. Berardi, U.; Iannace, G.; Trematerra, A. Acoustic treatments aiming to achieve the italian minimum environmental criteria (cam) standards in large reverberant. Can. Acoust. 2019, 47, 73-80.

21. Shtrepi, L.; Astolfi, A.; Puglisi, G.E.; Masoero, M.C. Effects of the Distance from a Diffusive Surface on the Objective and Perceptual Evaluation of the Sound Field in a Small Simulated Variable-Acoustics Hall. Appl. Sci. 2017, 7, 224. [CrossRef]

22. Visentin, C.; Pellegatti, M.; Prodi, N. Effect of a single lateral diffuse reflection on spatial percepts and speech intelligibility. J. Acoust. Soc. Am. 2020, 148, 122-140. [CrossRef]

23. Shtrepi, L.; Astolfi, A.; D'Antonio, G.; Guski, M. Objective and perceptual evaluation of distance-dependent scattered sound effects in a small variable-acoustics hall. J. Acoust. Soc. Am. 2016, 140, 3651-3662. [CrossRef] [PubMed]

24. Visentin, C.; Prodi, N.; Cappelletti, F.; Torresin, S.; Gasparella, A. Using listening effort assessment in the acoustical design of rooms for speech. Build. Environ. 2018, 136, 38-53. [CrossRef] 
25. Sanavi, A.; Schäffer, B.; Heutschi, K.; Eggenschwiler, K. On the Effect of an Acoustic Diffuser in Comparison with an Absorber on the Subjectively Perceived Quality of Speech in a Meeting Room. Acta Acust. United Acust. 2017, 103, 1037-1049. [CrossRef]

26. Lam, Y.W. A comparison of three diffuse reflection modeling methods used in room acoustics computer models. J. Acoust. Soc. Am. 1996, 100, 2181. [CrossRef]

27. Kjellberg, A.; Ljung, R.; Hallman, D. Recall of words heard in noise. Appl. Cogn. Psychol. 2008, 22, 1088-1098. [CrossRef]

28. Ljung, R.; Kjellberg, A. Long Reverberation Time Decreases Recall of Spoken Information. Build. Acoust. 2009, 16, 301-311. [CrossRef]

29. Ljung, R.; Israelsson, K.; Hygge, S. Speech Intelligibility and Recall of Spoken Material Heard at Different Signal-to-noise Ratios and the Role Played by Working Memory Capacity. Appl. Cogn. Psychol. 2012, 27, 198-203. [CrossRef]

30. Hygge, S. Classroom noise and its effect on learning. In Proceedings of the 11th International Congress on Noise as a Public Health Problem (ICBEN), Nara, Japan, 1-5 June 2014. Available online: http:/ / urn.kb.se/resolve?urn=urn:nbn:se:hig:diva-17206 (accessed on 10 April 2021).

31. Puglisi, G.E.; Prato, A.; Sacco, T.; Astolfi, A. Influence of classroom acoustics on the reading speed: A case study on Italian second-graders. J. Acoust. Soc. Am. 2018, 144, EL144-EL149. [CrossRef] [PubMed]

32. Astolfi, A.; Puglisi, G.E.; Murgia, S.; Minelli, G.; Pellerey, F.; Prato, A.; Sacco, T. Influence of Classroom Acoustics on Noise Disturbance and Well-Being for First Graders. Front. Psychol. 2019, 10, 2736. [CrossRef] [PubMed]

33. Bradley, J. Review of objective room acoustics measures and future needs. Appl. Acoust. 2011, 72, 713-720. [CrossRef]

34. Bradley, J.; Reich, R.; Norcross, S. A just noticeable difference in C 50 for speech. Appl. Acoust. 1999, 58, 99-108. [CrossRef]

35. BS EN ISO 354:2003: Acoustics. Measurement of Sound Absorption in a Reverberation Room. 2003. Available online: https: / / bsol.bsigroup.com/en/Bsol-Item-Detail-age/?pid=000000000030103215 (accessed on 10 April 2021).

36. Acoustics—Sound Absorbers for Use in Buildings—Rating of Sound Absorption (ISO 11654:1997). Byggakustik—LjudabsorbenterVärdering av Mätresultat och Klassindelning; SIS, Swedish Standards Institute: Stockholm, Sweden, 2002.

37. Prida, D.D.L.; Pedrero, A.; Azpicueta-Ruiz, L.A.; Navacerrada, M.Á.; Díaz, C. Does the method matter? A review of the main testing methods for the subjective evaluation of room acoustics through listening tests. In Proceedings of the Integrating 4th EAA Euroregio, Aachen, Germany, 9-13 September 2019. Available online: https:/ / search.datacite.org/works/10.18154/rwth-conv239793 (accessed on 10 April 2021). [CrossRef] 